\title{
Mood Adjustment via Mass Communication
}

By Silvia Knobloch

The author has proposed and experimentally tested the mood adjustment approach, complementing mood management theory. Participants were placed in an initial mood and led to anticipate different activities after the waiting period. The upcoming activities were either dynamic or lengthy (arousal) and associated with either pleasure or performance (valence), resulting in a $2 \times 2$ design. During an ostensible waiting period, participants listened to choices of popular music at their will in a computer-aided procedure. This music taken from the Top 30 charts had been evaluated in a pretest for energy and joyfulness as musical qualities in order to create sets of musical selections that were either low or high in these qualities. In the experiment proper, selective exposure to energetic-joyful music as dependent measure was unobtrusively recorded via software. Results regarding self-exposure across time show that patterns of music listening differ with initial mood and anticipation, lending support to mood adjustment hypotheses. Mood management processes occurred in the beginning of the waiting period, whereas mood adjustment purposes set in toward the anticipated activity.

Moods determine our outlook-how we look at the world, others, and ourselves. Although we often cannot change the world to our liking, we can influence our current affective perspective comparatively easily. In doing so, we take secondary control and manage our mood. Such coping behavior is very functional, given that anger and frustration due to unfavorable but unchangeable circumstances have been demonstrated to be unhealthy (e.g., Suinn, 2001). The aim of mood management widely consists of altering a disagreeable mood, enhancing a mediocre feeling state, or maintaining a pleasant mood. The media provide efficient stimuli to regulate one's mood, and access to this mood-regulating content is convenient and ubiquitous in modern civilization. Entertainment comprises a wide assortment of stimuli that are created to play on our emotions, which gives media consumers material to manage mood (Zillmann, 1988). Not surprisingly, we spend much of our leisure time with entertainment, from romance novels to video games. In fact, from a theoretical point of view conceptualized by Zillmann (1988), the motivation of self-exposure to media entertainment equals mood management

Silvia Knobloch is on the faculty of the Department of Communication Studies, University of Michigan at Ann Arbor. The author gratefully acknowledges support of the German Academic Exchange Service for the reported research and thanks Dolf Zillmann for a challenging discussion on the manuscript and Francesca Dillman Carpentier for supporting the project. Correspondence concerning this article should be addressed to email@silvia-knobloch.de. 
purposes. Empirical proof has been amassed for mood management theory. However, I suggest a complementing approach for those conditions in which the theory in its original sense does not apply (see Zillmann, 2000).

\section{Mood and the Media}

Moods have been called the "frame of mind" (Morris, 1990). They are central to human behavior because the feeling state strongly affects thinking (Bless, 1997), memory (Ellis \& Moore, 1999), perceptions of others (Forgas \& Bower, 1987), and perceptions of the self (Sedikides \& Green, 2001), as well as judgments on the environment in general (Mayer et al., 1992). Moods not only affect cognition and inner processes; their impact also materializes in everyday decisions (Hockey et al., 2000), performance (Hirt et al., 1996, 1997), and social interactions (Hertel et al., 2000). Thereby, moods have been referred to as a general "tuning" of the organism (Scherer, 1986, p. 181).

In light of these findings, high importance should be attached to media use for two reasons. First, the media, namely films, stories, and music, are known to influence moods (Westermann et al., 1996). Second, media consumption captivates long hours each day in the lives of typical Americans, more than 9.5 hours of all conventional media combined (Greenwald, 2000). Mediated stimuli, then, attain more or less subtle impact on the recipients' moods and, thereby, in part, set people's "frame of mind." Interestingly, music, as a category of the media that is said to have particular impact on mood, accounts for almost 38\% of total exposure time. On average, contemporary Americans spend at least $31 / 2$ hours a day listening to music provided by the radio, as well as by recordings (Greenwald, 2000).

\section{Mood Management Theory and Its Boundaries}

Research has established moods as a central factor for selective exposure to media. In particular, self-exposure to entertainment fare depends on current mood states of the recipients (e.g., Bryant \& Zillmann, 1977; Knobloch \& Zillmann, 2002; Meadowcroft \& Zillmann, 1987; Zillmann \& Bryant, 1986; Zillmann, Hezel, \& Medoff, 1980; Zillmann, Schweitzer, \& Mundorf, 1994). In addition, the feeling state influences news choices (Biswas, Riffe, \& Zillmann, 1994). As an empirically founded explanation, the mood management theory by Zillmann (1988) has become widely accepted. The theory emphasizes that self-exposure to media fare is motivated by hedonic purposes because media use is motivated by the goal of mood optimization. In more detail, the theory predicts that

the indicated hedonistic objective is best served by selective exposure to material that (a) is excitationally opposite to prevailing states associated with noxiously experienced hypo- or hyperarousal, (b) has positive hedonic value above that of prevailing states, and (c) in hedonically negative states, has little or no semantic affinity with the prevailing states. (Zillmann, 2000, p. 104)

Probably the most important challenge to this theory is the question of why one would ever turn to saddening or down-bringing entertainment content or to media offerings that intensify an adverse state-phenomena that are by no means rare (Mills, 1993; Oliver, 1993). With regard to such counterhedonistic media con- 
sumption, Zillmann (2000, p. 106) suggested an expansion of the time frame in which the ultimately desired mood is attained via mood management. An example for such behavior (see also below) would be that males, after being provoked, prefer aggression as media content. Thereby, males maintain their anger for later retaliation against the opponent to finally attain satisfying reprisal. This perspective is basically in line with an intended "delay of gratification" (e.g., Mischel, Shoda, \& Rodriguez, 1992) that possibly prevents self-exposure to cheerful content for the moment (Zillmann, 2000, p. 107). The mood-optimizing stimulus, then, lies clearly beyond media content, but in social interaction. Furthermore, the point of time when the goal of mood management, being mood optimization, is finally reached appears remote from the actual media exposure.

An approach complementing mood management theory appears more advantageous than expanding the original theory with regard to origin of mood change and time. Virtually all goal-directed behavior can be construed as maximizing delight or minimizing discomfort at some point along the line, but such an overly inclusive understanding does not appear optimal. Rather, a distinction between situations fostering mood management, in essence mood optimization by media use, and situations fostering mood regulations not aimed at hedonically optimal states seems more beneficial for empirical predictions. The following considerations will suggest an approach to that effect, providing explication in line with Zillmann's reasoning that "recognition of . . . limiting conditions should serve the prediction of spontaneous mood management better than speculations about anticipated hedonistic closure in a large time frame" (Zillmann, 2000, p. 109).

\section{Mood Adjustment Approach}

A hedonically optimal mood is not desirable under all circumstances. We frequently abstain from mood optimization because of social circumstances (e.g., at a funeral) or task-related requirements. In such cases, "Self-denial of mood improvement may prevent anyone who struggles with less-than-pleasant assignments from turning to more pleasant diversions" (Zillmann, 2000, p. 106). For instance, before taking a difficult exam, it would probably not help the candidate to be totally distracted from the upcoming test. Distraction, though, with all likelihood, would make the candidate feel better than full concentration on the unpleasant test situation. Hence, the person does not seek an optimal feeling state in hedonic terms, but tries to attain a state that is subjectively helpful for optimal test performance. The exam situation is a rather extreme example for the daily embracing of situational requirements. The same pattern applies to less challenging, less extreme situations such as driving during rush hour or writing a business letter. Under all these conditions, we may seek a sufficient level of concentration and composure instead of more enjoyable states of joyful exuberance. The object of mood regulation, then, is not mood optimization but mood adjustment. Whereas the given examples are concerned with adoption to cognitive requirements of a situation, mood adjustment via media use has been studied empirically in the context of adapting to social situations.

Erber, Wegner, and Therriault (1996) induced mood by exposing subjects to cheerful or depressing music and then asked them to rank cheerful, sad, and 
neutral headlines according to how much they would like to read the stories. Before ranking the headlines, half of the participants learned that they would perform a later, final task with a stranger. Results showed that participants not expecting any social interactions tended toward mood-congruent news material, whereas participants anticipating social encounters preferred mood-incongruent news. Erber et al. (1996) concluded that persons try to neutralize their feeling states before encountering unknown others. Findings of their second experiment indicate that knowing the other's feeling state affects mood regulation behavior, resulting in mood bolstering or neutralization efforts in cases of unmatched moods. O'Neal and Taylor (1989) found that annoyed males preferred violent and hostile programs only if they were led to believe they could work off their anger against the provoker in person. Thereby, they maintained their anger for the unfriendly encounter. In the contrasting case, wherein no opportunity for retaliation was anticipated, participants favored mood-enhancing content. As mentioned above, these examples differ from classic mood management patterns in that the desired optimal state is time-wise remote from media consumption and its anticipated origin is rooted in social interaction instead of media content. Accordingly, mood adjustment purposes motivate selective exposure in these cases.

Goals and anticipations. The anticipation of situational requirements is crucial for mood adjustment because this sets the object of the regulation. If there are no specific external requirements, mood can simply be optimized. If some requirements exist, but allow some scope, mood will be optimized within these constraints. Complications also arise for empirical investigations of mood adjustment because these requirements are, first, a perceived phenomenon and, second, anticipatory. Both mood management and mood adjustment, as theoretical concepts, can be categorized as expectancy-value models because the regulation measures are taken based on anticipated effects and circumstances (for mood management, see Knobloch, 2000). For the former model, however, such a categorization requires an assumption of at least minimal introspection during selfregulation. This assumption can be considered a contradiction, in theoretical terms, to the view that mood-management preferences result from operant conditioning (Zillmann \& Bryant, 1985, p. 187). Nonetheless, assumptions regarding the selfawareness do not affect predictions of actual media choices. For the latter approach, the regulation goal is conceptually more diverse than the very common purpose of mood optimization. According to mood adjustment, goals will vary with the context and individual motivation to meet perceived situational requirements. Factors in mood regulation are then not only the initial mood and accessibility of mood-inducing stimuli, but also the anticipated needs of mood adjustment. Additional intervening factors, such as conformity, relevant for adjustment to social encounters, or ambition, relevant to performance, will also play a role.

It should be noted that the two approaches diverge only with regard to empirical observations concerning situations that potentially require regulation other than optimization. Therefore, mood adjustment can be considered the more general model because it considers mood optimization as one goal in row with possible others. Unfortunately, the consideration of possible goals of mood regulation leads to a decidedly less parsimonious model. 
Time frame and development. Further complications result from the various time spans that can be monitored, as well as the fact that mood regulation progresses over time. This applies to mood adjustment in particular, because this pattern will develop with the approach of the activity requiring preparation-for instance, a cognitive task or a social encounter. In line with Zillmann's (2000) suggestion of "telic" mood management, the time frame and the development of the processes in question are considered essential and deserve special attention, especially in empirical investigations.

Frequency. Furthermore, research needs to address whether mood adjustment via self-exposure to hedonically unfavorable media content is a rare phenomenon or rather a frequent routine. Zillmann mentioned that "extreme emotional conditions exist in which persons fail to exercise the mood-modifying choices before them, despite the fact that these choices offer prompt relief from noxious states or enhancement of positive moods" (Zillmann, 2000, p. 109). However, such moodadjustment efforts, performed automatically or consciously, are likely to occur on a daily basis and not only under extreme conditions. One might, for example, watch a calming romance instead of a thriller to relax before going to bed, despite being bored. Likewise, a student working on a final paper might select classical music for this occasion, although being otherwise very partial to heavy metal music. In short, mood adjustment is a frequent phenomenon and by no means unusual.

Means. Individuals do not always succeed in their efforts to feel good or to attain an appropriate frame of mind. Failures of mood regulation can result from lack of efficient strategies or lack of efficient means. This leads to the question of how mood is actually managed. A vast body of psychological research has focused on strategies to optimize moods. Comparatively little is known of the actual process of mood adjustment, which is occasionally conceptualized in theoretical terms, but lacks empirical investigation (for an overview, see Gross, 1998, 1999).

For purposes such as mood repair or mood maintenance, a wide array of possibilities have been considered. Substances such as caffeine, alcohol, and nicotine alter alertness, and thereby mood, sometimes with negative effects up to dependency. Exercising, taking a hot bath, indulging oneself with food, shopping, or vacationing are other examples of efforts to regulate mood (Thayer, 1994). Mental control, in the form of concentrating one's thoughts on something that will influence the feeling state in the desired direction, has also been investigated (Wegner \& Wenzlaff, 1996). Interestingly, surveys investigating behaviors performed to influence mood (Rippere, 1977; Parker \& Brown, 1982; Gallup \& Castelli, 1989) have repeatedly shown that listening to music is among the most often reported strategies.

Among media entertainment, the area of music and music listening is frequently characterized as mood fixing, even psychologically healing (see, for instance, journals such as the Journal of Music Therapy). For example, music is used in films and commercials, also in shopping malls, to induce various feelings. It is also a common form of mood induction in psychological experiments. More pertinent, music is an easily accessible tool for mood regulation. Retrievable from the radio, 
recordings, computers, television, at home, at the workplace, and in the car, popular music delivers diverse mood expressions in 3-4 minute packages, any of which can serve to regulate mood. Thus, self-exposure to music is ideal for mood regulation purposes and is used accordingly, as demonstrated in empirical research (Knobloch \& Zillmann, 2002).

\section{Present Study}

The experimental study reported here aimed to operationalize crucial components of the mood adjustment approach and to demonstrate its importance. For this purpose, several difficulties need to be addressed regarding the aspects discussed above.

Goals and anticipations. To experimentally examine the mood adjustment process, anticipation of situational requirements must be induced. One way to generate anticipation would be to make an explicit announcement of the most favorable mental condition for the upcoming activity. This manipulation could clarify the situation and probably reveal distinct mood regulation efforts for each condition because idiosyncratic lay hypotheses on the preferable mood would be controlled. However, this approach does not carry much ecological validity. On the other hand, a general indication of the future activity better approaches real-life conditions. In the present study, activities that respondents already have performed will be declared to be continued. Hence, the variation of these activities will serve as experimental manipulation. Intervening effects of idiosyncratic interpretations of the announced activity could still be taken into account as a covariate in order to control this source of error variance. For an operationalization of this component, the analysis will use perceived situational requirements.

Frequency. Mood adjustment presumably occurs under ordinary and not only extreme circumstances. Hence, personal relevance of the experimental situation will need to be minimized so that the created situation mimics the mundane.

Means. Participants anticipating an upcoming activity supposedly take mood regulation steps. Accordingly, a set of mood-inducing stimuli in clear categories must be offered to them. The self-exposure to these stimuli, then, should be tracked precisely. Selective exposure to energetic and joyful music will serve as the indicator for mood-regulating behavior.

Time and development. To avoid confoundings due to varying time frames, the duration of mood regulation activities has to be scheduled explicitly. The research procedure must take into account the essence of time for mood adjustment by tracking regulation efforts. Inducing a mood before the regulation is expected can reduce error variance. Moreover, it allows an evaluation of mood management versus mood adjustment processes.

Hypotheses. To assess the explanatory power of the mood adjustment approach as a complement to mood management theory, I derived three hypotheses from each of the two models. Mood management theory would receive support if groups in different moods generally contrasted in their self-exposure to music regardless of upcoming activities. The mood adjustment approach would be supported empirically by self-exposure that changes over time, differing more with the approach of the anticipated activities. 
Hypotheses in accordance with mood management theory, which emphasizes the preoccupation with optimization of mood, can be stated as follows. In general, selection of, and exposure to, highly energetic and joyful music increases with negative mood quality.

H1: The preference for energetic-joyful music over alternatives is higher for persons in a mood with negative hedonic value than for persons in a mood with positive hedonic value.

H2: The preference for energetic-joyful music over alternatives is higher for persons with negatively experienced low arousal level (boredom) than for persons with neutrally experienced, moderate arousal level (composure).

H3: The preference for energetic-joyful music over alternatives is particularly high for persons in a negative and bored mood and particularly low for persons in a positive and composed mood.

The following hypotheses are in line with the mood adjustment approach, which stresses efforts over time to adapt to activities, not necessarily resulting in states that are optimal in hedonic terms. In general, selection of, and exposure to, highly energetic and joyful music varies with the anticipation of an upcoming activity.

H4: Persons anticipating a sober activity decrease their preference for energetic-joyful music as the activity approaches, whereas persons anticipating a playful activity increase it.

H5: Persons anticipating a dynamic activity decrease their preference for energetic-joyful music as the activity approaches, whereas persons anticipating a lengthy activity increase it.

H6: Persons anticipating a dynamic and sober activity decrease their preference for energetic-joyful music as the activity approaches, whereas persons anticipating a lengthy and playful activity increase it.

\section{Overview}

\section{Method}

In a computer-aided procedure, respondents performed an initial assignment designed to induce mood and manipulate their expectation about the following extended activity. To vary valence, this assignment was presented either as a funny game (playful with positive hedonic value) or a serious task (sober with negative hedonic value). The responsiveness of the assignment differed strongly to manipulate arousal (lengthy for boredom or dynamic for composure). For this $2 \times 2$ design, self-exposure to popular music while waiting for additional assignments served as the dependent variable. The songs offered for immediate listening had been rated in a pretest as being very high or very low in both energy and joyfulness. The music was also presented via computer software that unobtrusively recorded self-exposure to particular songs. After the waiting period, respondents gave a short indication of their current mood for a treatment persistence check and performed two additional assignments for closure. 


\section{Respondents}

Sixty-four undergraduate students at a large southeastern university in the United States participated in the experiment. They were recruited from introductory communication classes and received extra credit for participating. Respondents were evenly distributed across the four manipulated conditions resulting from hedonic valence and arousal (14, 16, 16, and 18, respectively). Participants were mostly female (46). The average age was 19.6 years. The gender proportion was consistent across the experimental groups. Within gender, the respondents were randomly assigned to the groups. An additional 53 respondents, drawn from the same population, rated the musical stimuli in a pretest.

\section{Pretest of the Musical Selections}

The 30 top hits of "The Billboard Hot 100" singles and airplay charts (Billboard \& BPI Communications, 2000) served as the starting point for the selection of songs. The songs were initially classified, on intuitive grounds, according to the dimensions slow-fast/soft-hard and negative-positive/sad-happy. The 16 songs that received extreme ratings and that were best differentiated in this mapping constituted the stimuli of the pretest. These songs were delivered via computer to the respondents' headphones.

The respondents evaluated each song, presented in its entirety, on eight 11point bipolar scales: fast-slow, hard-soft, cheerful-dreary, aggressive-peaceful, sad-happy, energetic-listless, exciting-relaxing, and sober-emotional. This set of scales was adapted (i.e., translated from German) from an instrument developed by Schaub (1981) that has been used frequently in research on music appreciation (Behne, 1984, 1986; Gembris, 1990). For every musical selection, the computer screen presented a set of scales. Between each pair of adjectives, it displayed an array of 11 gray rating boxes. Once a box was clicked, it turned red. The rating could be altered, however, until respondents decided to move on to the next musical selection. Only one rating could be made per scale, but one rating per scale was necessary to proceed. The rating scales were presented in the same order for all musical selections, whereas the sequence of the songs was individually randomized.

\section{Procedure}

General setting. Sessions were conducted in a computer laboratory with 17 identical personal computers. Up to 10 respondents participated simultaneously. The computers were located in open cubicles lining three adjacent walls. Initially, all computer screens were uniformly white, showing only the text: "Please wait for further instructions," along with a "start" box. An experimenter informed the respondents about the basic research objectives and procedures. After signing consent forms, participants initiated the procedures by pushing the start box. Although the delivery of instructions and experimental stimuli, as well as the collection of data, were fully automated, the experimenter remained present to answer possible questions and to prevent interaction among respondents.

Manipulation of mood and anticipated situation. Respondents learned that, after performing an initial assignment, they would have to wait for further assignments. The waiting period was justified by explaining that ergonomic data gath- 
ered during the first assignment would now undergo an extensive calculation. Initial mood and anticipation of the following, purportedly longer activity were manipulated according to the version of the initial assignment, which resembled a memory game. To manipulate the initial mood and the hedonic value of the anticipated situation, the initial assignment was described with the following instruction in two versions (wording for playful with positive valence in square brackets, for sober with negative valence in decorative brackets):

[Starting Game] \{Adjustment Task\} You will now [play] \{perform\} a first [game] $\{$ task\}. From the way you do this, we will learn about your habits of handling the computer mouse. Once you have finished this first [game] \{task\}, the mouse will be adjusted for the following [games] \{tasks\}. The adjustment is based on ergonomic data from a large sample of student participants. The computation will be run in the university's data processing center. This usually takes a few minutes. After the adjustment is made, you will be asked to [play more games] \{perform more tasks\} for about a quarter hour. The [games] \{tasks\} are exactly like the one you will [play] \{perform\} right now. This is how the first [game] \{task\} works: Click on the blue cards to uncover [comic characters] \{symbols\}. Only two cards can be turned around at a time. Each [comic character] \{symbol\} appears two times. You have to click on two identical cards in a row to get a match. Once all [characters] \{symbols\} are matched, the [game] \{task\} is over.

Participants were to match 10 pairs of icons, initially hidden behind square blue fields. Symbols in shades of gray served as icons for the task condition, whereas the game condition featured colorful cartoon characters. After two blue fields were clicked to uncover two icons, the pictures were covered after a certain period. To manipulate initial and anticipated arousal (hypo- versus medium arousal), this period was set to either 8 seconds to induce a lengthy activity or 1 second to create a dynamic activity. Furthermore, the audio feedback given after each trial to match icons differed due to assignment condition: When presented as a task, monotonous sounds served as audio feedback, whereas a triumphing brass and vibrating synthesizer sounds accompanied the game assignment. The respondents wore Sony MDR-201LP stereo headphones for digital recordings to hear these sounds and also the music presented later.

Music selection and duration of listening to songs. After the manipulation of mood and of anticipated activity, respondents were told that the information gathered by this initial assignment was computed for mouse adjustment in an extensive calculation. While waiting for the result, they could entertain themselves with music. The instruction read as follows and was emphasized by a blue bar purportedly indicating the file transfer to a data-processing center:

You have finished the first [game] \{task\}. Your data are now transferred to the data processing center for adjustment computation. You will proceed with more [games] \{tasks\} identical to the [game] $\{$ task\} you have already worked on. Before you can proceed, you have to wait for a few minutes until the computation is completed. Please remain seated to keep the session quiet! While you wait, you can listen to some popular music stored on this computer. Click on "continue" to get to the music and listen to whatever you like. 
For the next 7 minutes, the screen displayed the list of available songs and the text, "You can pick the music you enjoy and listen to it as long and as often as you wish. You can switch around between the songs as you like it. Please feel free to sample until you find the music you enjoy the most!" The list of songs was presented in individually randomized order. Eight buttons, each containing a song title along with the name of the song's performers, could be clicked for immediate access to the listed song. The 7 -minute listening period amounted to $23 \%$ of the time needed to listen to the eight songs in their entirety ( 30.5 minutes). This time restriction, about one third of total listening time, was necessary to ensure selectivity.

Once respondents clicked for the first time on a button, the 7-minute countdown started. Unbeknownst to the respondents, the selection of songs and the time spent listening to them were automatically recorded after each minute to track the mood-regulation process. Respondents were well aware of the remaining waiting time due to a feedback pattern commonly used in many kinds of software to indicate a waiting period. After every half minute of the scheduled 7 minutes, an additional small blue box appeared on a gray bar representing the whole time span. Thus, the progress of the ostensible computation of ergonomic data could be ascertained by viewing the number of blue boxes. After the designated time period expired, the software stopped the music and advanced the screen to a page that informed the participants that the adjustment computation was completed.

Perceived situational requirements. To attain an indicator of perceived situational requirements, respondents were asked to quickly indicate their current mood after the ostensible waiting period (a measurement before this period could have revealed the interests of the study and might have produce artifacts in the respondents' behavior). In order to stress a connection between the mood state and the activity, the measurement at this point of the procedure was justified toward subjects as follows: "Recent studies have shown that motor performance may be affected by mood state." Items used for this measurement were cheerful, tense, energetic, depressed, relaxed, and content. The response scheme provided "I do not feel ... at all" and "I definitely feel . . ." as descriptions of 0 and 10 of an 11-point scale.

\section{Results}

\section{Preliminary Analyses}

Classification of musical selections. For each respondent in the pretest, ratings were averaged on each of the eight scales across the 16 songs and subjected to factor analysis. Principal component extraction was followed by orthogonal rotation. Two factors materialized, accounting for $67.8 \%$ of the variance $(47.5 \%$ and $20.3 \%$, respectively). High loadings on the scales hard-soft (-.87), aggressive-peaceful (-.82), and fast-slow (-.78) defined the first factor along with minimal loadings on the second factor $(<|.25|)$. High loadings on the scales cheerful-dreary (-.84) and sad-happy (.81) described the second factor, as well as minimal loadings on the first factor $(<|.25|)$. The criterion combination of high loadings $(>|.67|)$ for 
factor-defining scales and minimal loadings for the alternative factor was not met by any other scale. The first factor was labeled "energy," the second "joyfulness." Interitem consistency confirmed the scale integration of both factors ( $\alpha=.82$ and .76, respectively).

The 16 songs were mapped two-dimensionally according to their mean scores on energy and joyfulness. The musical selections showing the best apparent differentiation formed two compilations of four songs, either high or low in energyjoyfulness. With ratings combined across the four songs in each group, a repeated-measures analysis of variance was performed on the factor measures. The analysis of energy yielded $M=2.18$ for low and $M=7.21$ for high; $F(1,52)=$ $507.20, p<.001$. That of joyfulness yielded $M=3.58$ for low and $M=6.93$ for high; $F(1,52)=134.71, p<.001$.

The selections constituting the high energy-joyfulness cluster were "All the Small Things" by Blink-182, "Then the Morning Comes" by Smash Mouth, "I Need to Know" by Marc Anthony, and "Bye Bye Bye" by 'N Sync. Those constituting the low energy-joyfulness cluster were "From the Bottom of My Broken Heart" by Britney Spears, "I Learned From the Best" by Whitney Houston, "Show Me the Feeling of Being Lonely" by Backstreet Boys, and "Back at One" by Brian McKnight.

Perceived situational requirements. The six items were condensed by a factor analysis that yielded two dimensions, accounting for $72 \%$ of the variance $(51 \%$ and $22 \%$, respectively). The first dimension labeled "tension" included tense (.85), relaxed (-.83), and content (-.81); the second dimension labeled "vivacity" covered energetic (.90), cheerful (.82), and depressed (-.65). The two factors were correlated by $r=-.44(p<.001)$. Interitem consistency $(\alpha=.81$ and .74, respectively) corroborated to integrate both factors by mean scores (after recoding in relation to factor loadings). Scores on these dimensions differed between experimental groups, thus attesting to the effectiveness of the manipulation. Tension was higher for the negative valence group compared to positive valence, $M=3.78$ vs. 2.83, $t(64)=1.88, p=.033$, one-sided $t$ test. Valence and arousal had an interaction effect on vivacity, $F(1,62)=4.25, p=.043)$, resulting in higher scores for the positive valence group compared to the negative valence group with both facing continuing with a lengthy activity ( $M=7.23$ vs. 5.78$)$.

\section{Selective Exposure to Music}

The sum of time spent on songs of both categories established in the pretest was computed for each participant. On average, respondents listened for almost exactly half of the time to energetic-joyful music (47\%, or 3:19 minutes). Because mood management theory does not make special reference to developments over time, a simple variance analysis with the experimental factors valence and arousal was applied to test $\mathrm{H} 1, \mathrm{H} 2$, and $\mathrm{H} 3$. It disclosed no significant effects on the total amount of time spent on energetic-joyful music. Hence, the analysis of selective exposure to music during the entire waiting period did not support the hypotheses derived from basic mood management theory.

The hypotheses based on the mood adjustment approach refer to the time dimension, as preferences are expected to increase or decrease, respectively. Furthermore, perceived situational requirements supposedly influence mood adjust- 
Preference for Highly Energetic-Joyful Popular Music

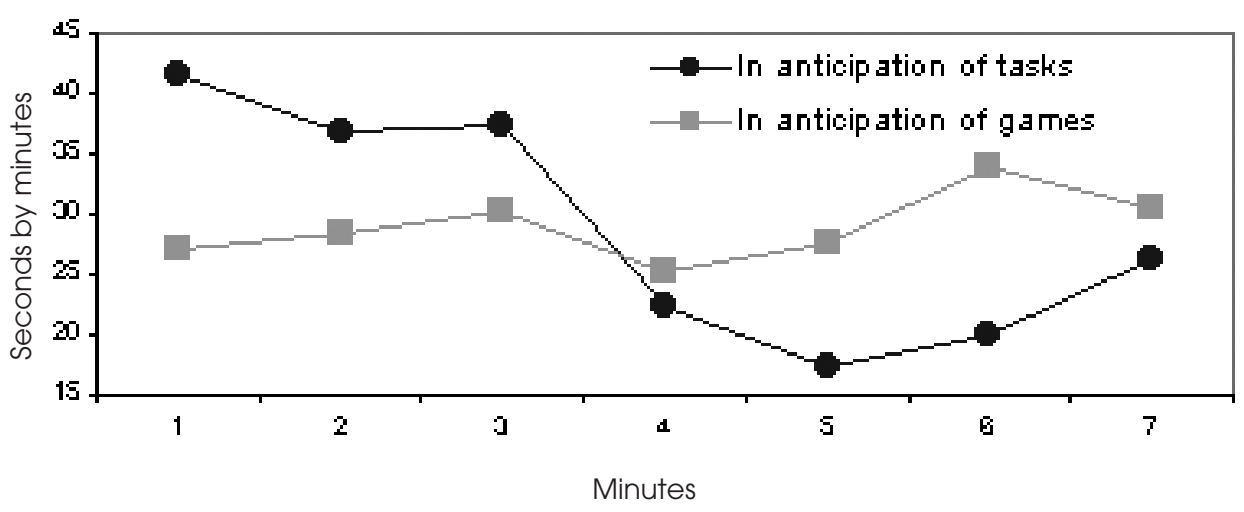

Figure 1.

ment processes. Accordingly, a mixed-measures analysis of variance with valence and arousal as factors and tension and vivacity as covariates was performed on repeated measures of self-exposure to energetic-joyful music over 7 minutes, each minute representing a measure. This analysis of variance yielded a main effect of time, $F(6,336)=3.66, p($ Greenhouse-Geisser corrected $)=.018$, an interaction between valence and time, $F(6,336)=3.32$, $p($ Greenhouse-Geisser corrected $)=$ .026 , and an interaction between valence, arousal, and time, $F(6,336)=3.65$, $p($ Greenhouse-Geisser corrected $)=.018$. Furthermore, vivacity as covariate proved significant, $F(6,336)=3.44, p($ Greenhouse-Geisser corrected $)=.023$. The remaining factors, including all between-subjects factors, did not reach significance. These effects on self-exposure to music can be described as mood-regulation processes with regard to the hypotheses $\mathrm{H} 4, \mathrm{H} 5$, and $\mathrm{H} 6$ as follows.

The interaction between valence and time indicates different developments of media use during the waiting situation in the two groups divided according to the experimental factor. Self-exposure in the experimental group expecting to play further games remained within a range of only 9 seconds - fairly stable and evenly spread across both types of music. Therein, only a very weak tendency to increase the preference for energetic-joyful music occurred. This indicates that, after having played a game and waiting to continue such an enjoyable occupation, subjects showed no particular partiality toward music high or low in energy-joyfulness. In contrast, subjects anticipating to work on further serious tasks showed a considerable range of 25 seconds. Their preference for energetic-joyful music is marked by a strong decline in the 4th minute. They dedicated about two thirds of the time to this music for the first 3 minutes, but only about one third during the next 3 minutes before reaching equivalent share of both types of music in the final minute (see Figure 1). 
These patterns offer support for H4. Obviously, participants in the game condition felt no need to regulate their mood at all. Subjects in the task condition showed markedly more effort to adjust their mood, indicated by a decrease in distracting exposure as hypothesized. Unexpectedly, though, they also increased exposure to this music in the very last minute, which is to be clarified later.

Effects of a hypo- or medium arousal level as postulated in $\mathrm{H} 5$ did not occur. However, the actual or anticipated arousal level did result in an interaction effect with valence and time, thus supporting H6. The processes of mood regulation differed substantially depending on the combination of valence and arousal levels. In detail, the two subgroups with high arousal and different valence showed significantly different selection patterns across time, $F(6,156)=7.17$, $p$ (GreenhouseGeisser corrected $)=.001$; selections of subjects with low arousal and low valence also differed across time from the behavior of the participants with high arousal and high valence, $F(6,174)=3.90, p($ Greenhouse-Geisser corrected $)=.015$. As expected, participants awaiting more dynamic tasks initially chose energetic-joyful music for the most part, but preferred dreary songs more and more while approaching further assignments.

The other development assumed in H6, regarding persons anticipating a lengthy activity with positive valence, did not materialize as postulated. This group showed a comparatively steady and equal consumption of both energetic-joyful and dreary music, although the respondents initially showed a slight preference for the former before turning more to dreary songs after the 4th minute. However, participants who expected to play further dynamic games increased their exposure to the more absorbing, energetic-joyful music over time.

In contrast, anticipation of a lengthy activity with a negative tone caused the most animated mood regulation process, beginning with a distinct preference for energetic-joyful music and then declining strongly and linearly until a turning point in the 5 th minute remarkably increased exposure again. It was this final increase that led to the general rise in the task condition mentioned above. This pronounced pattern of mood-regulating selection behavior is intelligible because of the comparatively disagreeable situation of this group of participants (see Figure 2). Taken together, dynamic assignments led to a preference contrasting the mission's tone shortly after completing the first round, but resembling it more and more toward the end of the waiting period.

The reported developments of self-exposure lent some support to H6 because, for the condition with dynamic tasks, the pattern materialized exactly as postulated, although persons anticipating a lengthy game did not increase the consumption of energetic-joyful music as expected. Still, the importance of anticipated valence and arousal as interacting factors emerged. Particularly, the strong changes in the exposure pattern of participants who were to perform a lengthy task can be interpreted as their adjustment efforts, wavering between concentration and distraction in quick succession.

\section{Supplementary Analyses}

The results described above give grounds for the assumption that processes as conceptualized in the mood management theory occurred only shortly after the 
Preference for Highly Energetic-Joyful Popular Music
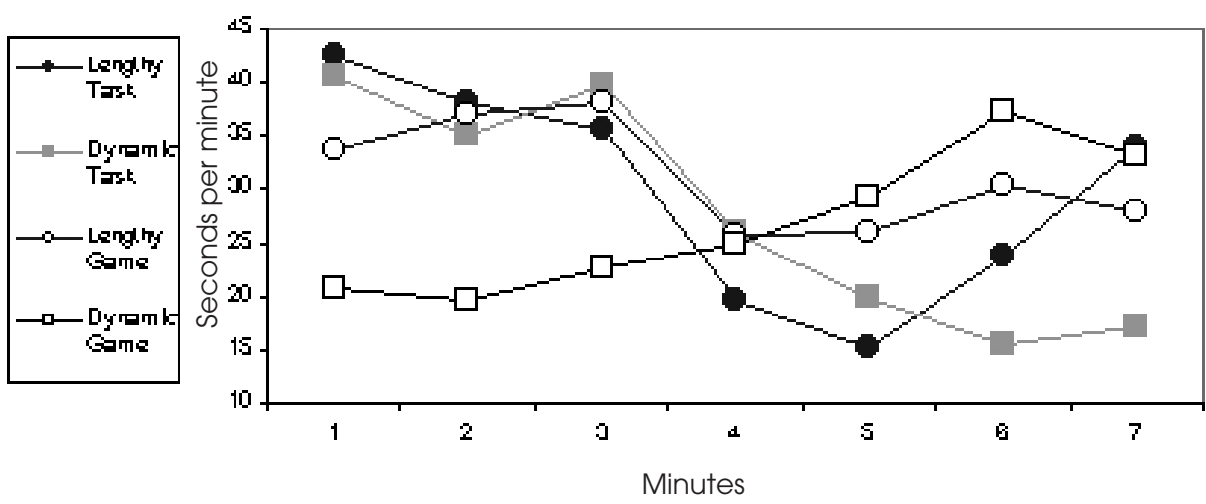

Figure 2.

initial assignment. In the beginning of the waiting period, subjects may have taken advantage of given leeway to optimize their feeling state because they did not have to prepare for further assignments right away. For an additional test of mood management assumptions, the sums of exposure to energetic-joyful music during the 1 st minute, the first 2 , and also the first 3 minutes were subjected to supplementary analyses of variance. Only valence had a significant effect on the music listening during the investigated time frame. In line with mood management theory, subjects in the task condition showed significantly more exposure to upbeat music, $M=43$ seconds vs. 27 seconds, $F(1,64)=5.19, p=.026$. For the first 2 minutes taken together, this main effect was marginally significant, $M=78$ vs. $56, F(1,63)$ $=3.40, p=.070$. For the 3 minutes time span, the effect of valence was negligible, $M=116$ vs. $86, F(1,63)=2.71, p=.105$.

Yet another explanation for the change after half of the given time span could assume that the respondents ran out of music pieces they liked and, hence, turned more to the songs they had not listened to before, although these songs did not meet their actual preferences. In this case, the choice developments did not reflect initial mood management behavior followed by choices guided by mood adjustment purposes, but only mood management that could not be pursued any further because of a lack of remaining alternatives. This explanation, though, can be ruled out for several reasons. First, the times of the songs taken together exceeded by far the scheduled waiting period, which accounted for $23 \%$ of aggregated song lengths. Second, an analysis of the logged song selection behavior showed that the majority of the respondents (61\%) listened to only four songs or less (for at least 5 seconds). Only six respondents sampled all eight songs available. Finally, a time-based reanalysis of an experiment on conditions fostering pure mood management via music (Knobloch \& Zillmann, 2002) substantiated that differences 
between mood manipulation groups in music selections persisted over 7 minutes, in contrast to the results of the present investigation.

\section{Discussion}

The analysis of selective exposure to popular music during a waiting period substantiated hypotheses derived from the mood adjustment approach. Supplementary inspections supported mood management assumptions as well. Respondents anticipating work on tasks sought to adjust their mood as this activity approached by decreasing their listening to distracting music in favor of smoother tunes. Anticipation of dynamic tasks especially resulted in exposure unmistakably motivated by adjustment because self-exposure to upbeat music continually decreased toward the activity, thereby fostering composure appropriate for such tasks. From a hedonic point of view in line with mood management theory, distraction from such an assignment would be preferable. Participants who were to perform an enjoyable game showed, in general, only a slight increase toward continuation of playing and may not have perceived any necessity to regulate their mood for this. However, the interplay of pace and valence of the anticipated activity created very different adjustment patterns, only partly converging with a priori assumptions. This can be explained by conflicting requirements, for example, a lengthy task for which concentration would be advisable but also disagreeable. Hence, the mood adjustment approach proved to be very promising for further predictions of selective exposure.

Mood adjustment as self-regulation via media exposure, which presumes a very functional media use, received remarkable support in this pioneering study. However, the nature of the sample (undergraduates) and the predominance of females (exploratory analyses did not reveal any appreciable gender effects) are limitations to generalizability. A replication of the study with other parts of the general population and larger, more balanced samples is desirable. Nevertheless, future research should not necessarily predict increases and decreases as hypothesized here, because such developments depend strongly on initial moods that may not always allow changes (e.g., because of ceiling effects) in the directions that were assumed in this study.

It should be emphasized that mood management in the sense of optimization is a very broad common denominator and thereby applicable to many situations of media use. As mentioned, within a given scope, mood will be optimized within existing constraints and requirements. In fact, the presented data can be reinterpreted as follows. During the first 3 minutes, the participants who had worked on a task aimed to regulate their mood by selecting cheerful music, but turned to calming music as the next task approached. In contrast, gamers showed no particular preference for cheerful or calming music. The most animated mood-regulation pattern was found for participants who were in the least agreeable situation because they had to work on tasks at a very tedious speed. Although given the scope of pursuing hedonically preferable stimulation, respondents who had performed less then agreeable activities acted on this opportunity. With more tasks 
coming about, subjects made an effort to concentrate, but then discontinued their concentration in favor of a more cheerful stimulation that would combat anticipated boredom.

Considering this interpretation, the results speak for both conceptualizations of mood regulation processes. Post-hoc scrutiny of these selective exposure processes reveals patterns of mood management, as well as patterns of mood adjustment. Mood optimization applied shortly after mood induction, whereas mood adjustment pertained shortly before continuation of action. The well-established mood management theory supplemented by the mood adjustment approach, then, forms a comprehensive and detailed theoretical framework for mood-related media use. Selective exposure to distressing media content, the primary challenge of the mood-management theory, can be explained with the mood adjustment approach. Future research should investigate possible goals of mood regulation via media exposure, perceived scope in doing so, use of various media fare, and relevant time frames, in addition to relevant individual differences. The procedure used in this study may still be improved by separate manipulation of initial mood and anticipated mood requirements. ${ }^{1}$ Such a methodological refinement, however, is only worthwhile if mood adjustment efforts do not overwhelm mood optimization interests. Depending on the upcoming activity, the initial mood along with the purpose of its optimization may have markedly less impact on selective exposure to mass communication than anticipated mood requirements.

${ }^{2}$ The author would like to thank an anonymous reviewer for raising this issue.

\section{References}

Behne, K.-E. (1984). Befindlichkeit und Zufriedenheit als Determinanten situativer Musikpräferenzen. Jabrbuch Musikpsychologie, 1, 7-21.

Behne, K.-E. (1986). Die Benutzung von Musik. Jahrbuch Musikpsychologie, 3, 11-31.

Biswas, R., Riffe, D., \& Zillmann, D. (1994). Mood influence on the appeal of bad news. Journalism Quarterly, 71, 689-696.

Bless, H. (1997). Stimmung und Denken. Ein Modell zum Einfluß von Stimmungen auf Denkprozesse. Bern, Switzerland: Hans Huber.

Bryant, J., \& Zillmann, D. (1977). The mediating effect of the intervention potential of communications on displaced aggressiveness and retaliatory behavior. In B. D. Ruben (Ed.), Communication yearbook 1 (pp. 291-306). New Brunswick, NJ: Transaction Press.

Erber, R., Wegner, D. M., \& Therriault, N. (1996). On being cool and collected: Mood regulation in anticipation of social interaction. Journal of Personality \& Social Psychology, 70, 757-766.

Ellis, H. C., \& Moore, B. A. (1999). Mood and memory. In T. Dalgleish \& M. J. Power (Eds.), Handbook of cognition and emotion (pp. 193-210). Chichester, UK: Wiley.

Forgas, J. P., \& Bower, G. H. (1987). Mood effects on person-perception judgments. Journal of Personality \& Social Psychology, 53, 53-60.

Gallup, G., Jr., \& Castelli, J. (1989). The people's religion. New York: Macmillan.

Gembris, H. (1990). Situationsbezogene Präferenzen und erwünschte Wirkungen von Musik. Jabrbuch Musikpsychologie, 7, 73-95. 
Greenwald, T. (2000, May). Mass distraction: Media consumption in dollars and hours. Wired, 8, p. 105.

Gross, J. J. (1998). The emerging field of emotion regulation: An integrative review. Review of General Psychology, 2, 271-299.

Gross, J. J. (1999). Emotion regulation: Past, present, future. Cognition E Emotion, 13, 551-573.

Hertel, G., Neuhof, J., Theuer, T., \& Kerr, N. L. (2000). Mood effects on cooperation in small groups: Does positive mood simply lead to more cooperation? Cognition E Emotion, 14, 441-472.

Hirt, E., Levine, G. M., McDonald, H. E., Melton, R. J., \& Martin, L. L. (1997). The role of mood in quantitative and qualitative aspects of performance: Single or multiple mechanisms? Journal of Experimental Social Psychology, 33, 602-629.

Hirt, E., McDonald, H. E., \& Melton, R. J., (1996). Processing goals and the affect-performance link: Mood as main effect or mood as input? In L. Martin \& A. Tesser (Eds.), Striving and feeling: Interactions among goals, affect, and self-regulation (pp. 303-328). Hillsdale, NJ: Erlbaum.

Hockey, G. R. J., Maule, A. J., Clough, P. J., \& Bdzola, L. (2000). Effects of negative mood states on risk in everyday decision making. Cognition E Emotion, 14, 823-856.

Knobloch, S. (2000). Schicksal spielen: Interaktive Unterhaltung aus handlungstheoretischer und persönlichkeitspsychologischer Sicht. Munich, Germany: Reinhard Fischer.

Knobloch, S., \& Zillmann, D. (2002). Mood management via the digital jukebox. Journal of Communication, 52, 351-366.

Mayer, J. D., Gaschke, Y. N., Braverman, D. L., \& Evans, T. W. (1992). Mood-congruent judgement is a general effect. Journal of Personality \& Social Psychology, 63, 119-132.

Meadowcroft, J. M., \& Zillmann, D. (1987). Women's comedy preferences during the menstrual cycle. Communication Research, 14, 204-218.

Mills, J. (1993). The appeal of tragedy: An attitude interpretation. Basic and Applied Social Psychology, 14, 255-271.

Mischel, W., Shoda, Y., \& Rodriguez, M. L. (1992). Delay of gratification in children. In G. Loewenstein \& J. Elster (Eds.), Choice over time (pp. 147-164). New York: Russell Sage Foundation.

Morris, W. (1990). Mood: The frame of mind. New York: Springer.

Oliver, M. B. (1993). Exploring the paradox of the enjoyment of sad films. Human Communication Research, 19, 315-342.

O'Neal, E. C., \& Taylor, S. L. (1989). Status of the provoker, opportunity to retaliate, and interest in video violence. Aggressive Behavior, 15, 171-180.

Parker, G. B., \& Brown, L. B. (1982). Coping behaviors that mediate between life events and depression. Archives of General Psychiatry, 39, 1386-1391.

Rippere, V. (1977). What's the thing to do when you're feeling depressed-A pilot study. Behavior Research and Therapy, 15, 185-191.

Schaub, S. (1981). Zum Einfluss situativer Befindlichkeit auf die musikalische Erwartung. Musiktherapeutische Umschau, 2, 267-275.

Scherer, K. R. (1986). Emotion experiences across European cultures: A summary statement. In K. R. Scherer, H. G. Wallbott, \& A. B. Summerfield (Eds.), Experiencing emotion: A cross-cultural study (pp. 173-189). Cambridge, UK: Cambridge University Press.

Sedikides, C., \& Green, J. D. (2001). Affective influences on the self-concept. Qualifying the moodcongruency principle. In J. P. Forgas (Ed.), Handbook of affect and social cognition (pp. 145-160). Mahwah, NJ: Erlbaum. 
Suinn, R. M. (2001). The terrible twos-anger and anxiety: Hazardous to your health. American Psychologist, 56, 27-36.

Thayer, R. E. (1994). The biopsychology of mood and arousal. New York: Oxford University Press.

Wegner, D. M., \& Wenzlaff, R. M. (1996). Mental control. In E. T. Higgins \& A. W. Kruglanski (Eds.), Social psychology: Handbook of basic principles (pp. 466-492). New York: Guilford Press.

Westermann, R., Spies, K., Stahl, G., \& Hesse, F. W. (1996). Relative effectiveness and validity of mood induction procedures: A meta-analysis. European Journal of Social Psychology, 26, 557-580.

Zillmann, D. (1988). Mood management: Using entertainment to full advantage. In L. Donohew, H. E. Sypher, \& E. T. Higgins (Eds.), Communication, social cognition, and affect (pp. 147-171). Hillsdale, NJ: Erlbaum.

Zillmann, D. (2000). Mood management in the context of selective exposure theory. In M. E. Roloff (Ed.), Communication yearbook 23 (pp. 103-123). Thousand Oaks, CA: Sage.

Zillmann. D., \& Bryant, J. (1985). Selective-exposure phenomena. In D. Zillmann \& J. Bryant (Eds.), Selective exposure to communication (pp. 1-10). Hillsdale, NJ: Erlbaum.

Zillmann, D., \& Bryant, J. (1986). Shifting preferences in pornography consumption. Communication Research, 13, 560-578.

Zillmann, D., Hezel, R. T., \& Medoff, N. J. (1980). The effect of affective states on selective exposure to televised entertainment fare. Journal of Applied Social Psychology, 10, 323-339.

Zillmann, D., Schweitzer, J. J., \& Mundorf, N. (1994). Menstrual cycle variation of women's interest in erotica. Archives of Sexual Behavior, 23, 579-597. 